\title{
"Charges are everywhere": A case of student sensemaking about electric current
}

\author{
Tor Ole B. Odden ${ }^{1}$ and Rosemary Russ ${ }^{1}$ \\ ${ }^{1}$ Department of Curriculum and Instruction, University of Wisconsin-Madison, Madison, WI 53706, USA
}

\begin{abstract}
In recent years, there has been a growing interest in how students make sense of physics concepts, but there is as of yet little consensus on what it actually means for students to "make sense" of physics. We propose a theoretical model for the sensemaking process synthesized from the science education research literature on sensemaking. We then illustrate the model with a case study of two introductory physics students articulating and resolving an inconsistency in their understanding of electric circuits in a clinical interview context. We show how the students' transitions in discourse and framing fit with the model, and argue that this sensemaking process is driven by a particularly vexing inconsistency in knowledge.
\end{abstract}

\section{INTRODUCTION}

Sensemaking has been a growing topic of study both in the general science education research literature and in PER. Within PER, much of this interest seems to stem from the understanding that we want our students to be able to do more than just produce correct answers to physics problems (often called answer-making) [1]. While problem solving is certainly important, we also want students to see that physics knowledge applies beyond idealized problems or simplified lab experiments, to feel that it's coherent with their understanding of the world - that it "makes sense." But in order to help students make sense of physics, we first need to understand both what it means for them to make sense and how they do so.

Educational researchers have studied sensemaking from a variety of perspectives. Some have studied it as a stance that students take towards science learning, a way that they frame their activities. From this perspective, students who are trying to make sense of physics are approaching the subject with a specific goal, to build an explanation that achieves coherence between the principles we teach and what they otherwise know to be true about the world [2-4]. Other researchers have studied it as a cognitive process that students engage in, in which they connect and integrate new, formal knowledge with their existing knowledge. Within PER specifically, there has been a particular focus on how students create connections between different types of representations, such as formal mathematics, pictorial representations, embodied representations or gestures, and graphs [3, 5, 6]. Still other researchers have studied sensemaking as a discursive activity, looking at the ways in which students' talk helps them to make sense of new knowledge. This research highlights the essential role of argumentation to sensemaking: students engage in an iterative cycle of constructing and critiquing ideas [7]. However, while their behavior may resemble what we typically think of as "arguing," their goal is to articulate and strengthen their ideas, rather than to "win" an argument [8].

These areas of sensemaking research have so far mostly remained separate. Our initial goal in studying sensemaking was therefore to assemble them into a complete, coherent description, which we could then use to examine the ways in which students approach sensemaking. After reviewing and synthesizing these strands of science education research literature, we define sensemaking as a process in which students build and critique an explanation in order to resolve a gap or inconsistency in their understanding. However, while this definition, and the literature it is based on, provides numerous characteristics of sensemaking, it provides less information about how it begins (i.e., how to get students to engage in sensemaking in the first place) or how it proceeds once the process has begun. So, based on this initial definition, we aimed to investigate and characterize this process in greater detail, trying to understand both how it begins and how it unfolds.

\section{METHODS}

The data for this project comes from a series of semistructured clinical interviews [9] with pairs of introductory physics students. These students were enrolled in a largelecture, algebra-based, second-semester E\&M course at a large Midwestern University. The first author (Odden) interviewed each pair five times throughout the semester. Each interview targeted a particular concept such as charges, electric fields, electric potential, or electric current, usually a week after the students had covered that topic in class.

Interviews typically lasted about an hour. The interview prompts were designed to encourage the students to build explanations around demonstrations (such as charged rods, charged tape, or circuit boards) and thought experiments related to topics the students had discussed in class. Examples include questions like "where is the safest place to grab an electric eel?" or "is it safe to leave your car immediately after it's been struck by lightning?" Students were interviewed in pairs to increase the likelihood that they would critique one another's reasoning and to decrease the likelihood that they would get "stuck" while building explanations.

Interviews were video and audio recorded, transcribed, and analyzed to identify episodes in which the students noticed an inconsistency in their explanation or an idea that didn't "make sense" to them. We then analyzed these episodes using construct of framing, based on the work of Russ et al. [9] and Kapon [4] . Framing is commonly understood as a person's sense of "what's going on here?" [10], their task or 
goal for a particular activity. We identified these framings using cues in their language (both verbal and non-verbal, such as hesitations and restarts), body language/positioning, and overall behavior [11]. We also examined the students' dialogue from a discourse-analytic perspective, noting the specific ideas brought up during their explanations, the ways in which they built on or critiqued each other's ideas, and the ways they eventually resolved these inconsistencies (when they were successful).

\section{A MODEL OF THE SENSEMAKING PROCESS}

Based on our definition of sensemaking, as well as the patterns in student framing and dialogue across our analyzed excerpts, we propose the following model of the process:

1. Students start by assembling a framework of knowledge, laying out their ideas on a subject in response to some question, prompt, or task.

2. They then notice and articulate a gap or inconsistency in that framework, something that doesn't "fit" or which is unexplained and vexing to them.

3. They try to build an explanation that fills in the gap or reconciles the inconsistency, but return to the question when they find flaws in this explanation. In this way, the explanation-building process is iterative, and may give rise to sub-questions that they pursue in turn.

4. In some cases, students successfully assemble an explanation that feels satisfactory and resolves the inconsistency or fills in the gap. At this point things "make sense" to them. In others, they give up out of frustration or exhaustion and move on.

This model encapsulates the three strands of sensemaking research: in the first stage students activate their prior knowledge, providing the "raw material" for the cognitive process of sensemaking. In the second, their goal or framing shifts to reconciling a gap or inconsistency in knowledge. In the third, they construct and critique an explanation, drawing on both their prior knowledge and (potentially) various representations of phenomena. In the final stage, they either accept this explanation or give up out of frustration.

Within this sensemaking process, a critical moment occurs when the students attend to and articulate an inconsistency or gap in their understanding, the thing that doesn't "make sense" to them. We call this articulation the vexation point. In our model, it is what kicks off the sensemaking frame, the point where students transition from recalling previously learned knowledge to actively building new knowledge or new connections between ideas.

While this model bears some similarity to other theories of knowledge building, including Piagetian assimilation and accommodation [12], and discrepant events [13], we see it as distinct for two reasons: first, vexation points are generalized inconsistencies or gaps in knowledge. They my be triggered by phenomena that behave differently than expected, but they may also be triggered when a student realizes that they simply don't understand a particular subject as well as they thought they did. Second, this process takes place on a much smaller scale than assimilation and accommodation, which are usually described as creating large-scale shifts in understanding. Sensemaking, in contrast, takes place on a shorter timescale (typically a few minutes) and is more akin to "debugging" one's knowledge to address a particular gap or inconsistency.

In what follows, we illustrate this model of sensemaking using a case study of a pair of students articulating and resolving a vexation point related to electric circuits.

\section{ILLUSTRATION OF THE MODEL}

This particular case comes from a circuits-based interview with two students, Ruth and Emma. The episode was chosen both for its clarity and its brevity. Ruth and Emma were good friends, and both were biology majors. Both had previously taken a first-semester algebra-based mechanics course, and Ruth had additionally taken physics in high school.

At about 40 minutes into the interview, the interviewer has provided Ruth and Emma with a powered circuit board, various resistors and wire segments, several lightbulbs, and a challenge to construct two circuits: one that would make a lightbulb shine as brightly as possible and another that would make it shine as dimly as possible. As they do, he asks them to explain their thinking.

To make the bulb shine brightly, the pair have constructed a parallel circuit out of the three lightbulbs provided, and have verified that the voltage drop across each branch is the same. Next, the interviewer presses them to talk more about their understanding of the difference between current in a series circuit vs. parallel circuit, asking them specifically how the current coming out of the power supply would compare between the two. This prompts Emma to recall Kirchoff's current rule.

E : "Yeah, so this is $I_{\text {total }}$, and then it's like $I_{1}, I_{2}, I_{3}$. And $I_{1}, I_{2}, I_{3}$ is equal to $I_{\text {total }}$, and then they all become $I_{\text {total }}$ again right before they go in [to the battery]."

In response, the interviewer clarifies his question, asking them to compare the total current in a series circuit to that of a parallel circuit.

I : But, I guess I'm asking, like, if you compared $I_{\text {total }}$ now to the $I_{\text {total }}$ you had before [in the series circuit], when-

E : It should be the same.

This statement prompts some discussion between the two students: is the net current, in fact, the same in a series vs. parallel circuit? After calculating both the current through the individual resistors and the overall current through the circuit 
they conclude that the net current is different between series and parallel circuits, which prompts a strong reaction:

$\mathrm{R}:$ Oh, that's counter-intuitive, yeah.

E : Yeah, that sucks. That's super counter-intuitive. Why would a current be bigger, just coming out of the voltout of the battery?

$\mathrm{R}$ : Because it's the same-

E : No, but you know, okay, like, subjectively, there's just, okay, ignore everything past this. \{Emma puts her hand over the circuit\} Coming out of the battery, why wouldn't it be the same current to begin with? In the $\mathrm{s}-$ you know what I mean?

At this point in the interview, we claim that the students have progressed through the first two steps in our model of sensemaking. The interviewer has posed a question which gets the students started in their reasoning process. They "laid out" their initial ideas on the subject, which mostly consisted of mathematical rules for calculating current, along the lines of what Tuminaro and Redish have called "Mapping Mathematics to Meaning" [3]. However, as the discussion proceeded, Emma noticed an inconsistency in her understanding: it seems counter-intuitive that the battery sends more current down to the parallel circuit-power sources shouldn't change their behavior depending on what's attached to them. The pair spend the remainder of the episode looking for some way to resolve this inconsistency, indicating that this question is their vexation point, the inconsistency that drives their sensemaking.

The students' dialogue and framing so far also fit with the model. Early in the episode, when they are discussing and calculating the total current in the circuit, their framing matches what Russ et al. [9] call an "inquiry frame": the two are speaking slowly, hesitantly, staring off into space. Dialogically, they are building off of or augmenting each other's statements, not critiquing each other's reasoning. Essentially, they seem to be trying to brainstorm what they know about series and parallel circuits. At the point where Emma verbalizes her question however, we see the beginnings of a transition in dialogue and framing: both students become more animated, make eye contact with each other, begin to speak quickly and fluidly, and gesture more often. Rather than simply building off of each other's ideas, their dialogue starts to become more argumentative.

The episode continues as Ruth tries to answer Emma's question, "why wouldn't it be the same current to begin with?":

$\mathrm{R}$ : Because here the resistance is smaller. Because the equivalent resistance is, is 1 over four plus four plus fou-whatever we said that each resis-three plus three plus three. And so, since, or it's like a third plus a third plus a third.

Ruth and Emma discuss the math a bit more, before returning to the question Emma posed:
E : I know, but what I'm saying is like if you just have a circuit, \{Emma draws a small circuit\} the current coming out right away, right? \{Emma draws an arrow coming out of the battery\} Before you're looking at anything here, whether it's parallel or in series, why wouldn't that current be the same?

$\mathrm{R}$ : Because there's less resistance-

E : But it hasn't approached the resistance yet.

$\mathrm{R}$ : But I think it just knows.

E : It just knows?

Here, the shift in behavior is clear. The students are animated, making eye contact with each other, with gestures and turns of talk coming in quick succession. Their dialogue also has shifted fully into cycles of construction and critique which researchers have argued is characteristic of sensemaking [7, 8]. From a framing perspective, their task or goal seems to have shifted from "dredging up knowledge" to trying to achieve coherence between what Emma thinks should be true (batteries can't "know" how much current to send to the circuit) and what they've observed-sensemaking, in other words.

In terms of our model of the sensemaking process, Ruth and Emma are now engaged in the third step, a cyclical process of trying to build an explanation that resolves the inconsistency. Mathematical arguments seem to be insufficient, as are teleological explanations ("It just knows"). And as each argument or explanation is rejected, Emma returns to her question, which drives the pair into their next cycle of explanation. So, what is Emma looking for? The discussion continues:

R : It kno-like it, it's like, this voltage is stuck, and so it can't change how many volts are being put out, so the only-and it can't change what resistors are out and what orientation. So it can only change this current. It can only decide how fa-er, how, yeah, how much it, charge can move in,

E : Right, I understand that, once it [the current] gets to like this node. \{Emma points to the first junction\} But I don't get how it [the battery] would know what's coming [further down the circuit] from here. You know what I'm saying?

R : I think it's just that charges are everywhere. But no, I, I see what you're saying, but I also don't think we're seeing it from that perspective.

E : Yeah, I guess I'm also, yeah, I guess I'm also thinking about it as, like, the charge starts right here, but really it's like always all moving. Yeah.

Feeling like they've come close to resolving Emma's question, the interviewer presses them to explain what they've established. They explain,

$\mathrm{R}$ : Well, like, if we think about it, we don't have, like, when we have a circuit put together, and the minute 
we put the lightbulb in, it turns \{snaps fingers\} on. ... It's the fact that because this wire is connected, there's charges all over, and so even though they're, the current is what's driving the charge around, there's already charge built up in here, so by the time I put it in, that, it starts everything moving. So the second everything starts moving, I'm gonna get, there's gonna be things moving here, here, here, everywhere.

E : Yeah. That's what I was missing. Is that, like, I can't think of this as independent from everything else.

Based on this explanation, it seems that what Emma was looking for was some kind of mechanism [14] that would make their mathematical results consistent with what she otherwise knew to be true (batteries can't "tell" what they're hooked up to). For her, the notion that "charges are everywhere" throughout the circuit made that connection, achieving coherence [15] and filling in what she was "missing."

Some might argue that Emma had a common misconception about circuits, that net current is the same in both series and parallel. However, misconceptions are canonically described as being stable and hard to change (e.g., Ref [16]) whereas Emma seemed to be willing to change her mind on the subject the moment she saw that series and parallel circuits had different currents. In other words, Emma had already accepted this difference, and was now looking for some way to align her observation with everything else she knew about circuits, batteries, and current. For her, that alignment happened through the idea that "charges are everywhere" throughout the circuit.

During this last segment, we see one more transition in framing, after the students have settled on a resolution and the interviewer presses them to explain their conclusion. Where before they were in an animated discussion, exchanging quick bursts of dialogue, they now both turn to the interviewer and speak authoritatively, explaining the conclusion they've come to. Here, their framing resembles what Russ et al. [9] called the "expert interview frame," as they face the interviewer, speaking fluidly and authoritatively, with frequent gestures. Their "task" seems to have changed to transmitting the knowledge they've constructed to the interviewer. Such behavior fits with the final step of our model.

It's interesting to note that during this period, Emma continues to cycle back to her question. Even as Ruth and Emma try to answer it mathematically ("the equivalent resistance is..."), teleologically ("it just knows") and eventually mechanistically ("charges are everywhere"), they continue to return to the question, which acts as the starting point for each cycle of dialogue. This, we suggest, is evidence that the vexation point does more than just kick off the students' sensemaking: it actively drives them through the process, pulling them back to the question at hand after each attempt at an explanation.

\section{DISCUSSION AND CONCLUSION}

This is an initial model of the sensemaking process; while grounded in the sensemaking literature, it is at present still fairly theoretical. As such, more research needs to be done to see if it holds with other groups of students in other environments. However even in its current form, it, along with the illustrative case, provides some suggestions for both where to look for sensemaking in future studies and why we would want students engaging in sensemaking in the first place.

In terms of places to look for sensemaking, this model suggests that we would expect it to occur most often in learning environments where students have a chance to articulate and pursue their gaps or inconsistencies in knowledge. These environments would ideally include a focus on dialogue between students to give them a chance to formulate questions, build explanations, draw on their prior knowledge and experiences, and critique each others reasoning.

This example also implies that when students are given a chance to articulate and pursue a vexation point, it can stimulate connections that might otherwise be missed. Emma's point that "charges are everywhere" is really quite a sophisticated mechanistic explanation [14], and this wholistic view of circuits is a powerful compliment to the formal, rules-based approach she drew on early in the excerpt. By continuing to study and support sensemaking, we hope to help more students like Emma make these types of conceptual connections.
[1] Y. Chen, P. W. Irving, and E. C. Sayre, Phys. Rev. Spec. Top. Phys. Educ. Res. 9, 1 (2013).

[2] A. Gupta and A. Elby, Int. J. Sci. Educ. 33, 2463 (2011).

[3] J. Tuminaro and E. Redish, Phys. Rev. Spec. Top. - Phys. Educ. Res. 3, 20101 (2007).

[4] S. Kapon, Sci. Educ. (2016).

[5] E. Gire and E. Price, Phys. Rev. Spec. Top. - Phys. Educ. Res. $10,(2014)$.

[6] F. Jeppsson, J. Haglund, T. G. Amin, and H. Strömdahl, J. Learn. Sci. 22, 70 (2013).

[7] M. J. Ford, Cogn. Instr. 30, 207 (2012).

[8] L. K. Berland and B. J. Reiser, Sci. Educ. 93, 26 (2009).
[9] R. S. Russ, V. R. Lee, and B. L. Sherin, Sci. Educ. 96, 573 (2012).

[10] D. Tannen, Framing in Discourse (1993).

[11] R. E. Scherr and D. Hammer, Cogn. Instr. 27, 147 (2009).

[12] H. P. Ginsburg, Piaget's Theory of Intellectual Development: An Introduction (1987).

[13] T. L. Liem, Invitations to Science Inquiry, 2nd ed. (1991).

[14] R. S. Russ, R. E. Scherr, D. Hammer, and J. Mikeska, Sci. Educ. 92, 499 (2008).

[15] T.-R. Sikorski and D. Hammer, Sci. Educ. 1 (2017).

[16] G. J. Posner, K. A. Strike, P. W. Hewson, and Wi. A. Gertzog, Sci. Educ. 66, 211 (1982). 